folgern aus den Ergebnissen dieser Studie, dass Romiplostim bei der überwiegenden Anzahl der Kinder mit ITP die Thrombozytenzahl deutlich erhöhen kann und gut vertragen wird.

Bussel JB et al. A randomized, double-blind study of romiplostim to determine its safety and efficacy in children with immune thrombocytopenia. Blood 2011; 118: 28-36
Kommentar: Die Ergebnisse der Studie zeigen eindrucksvoll, dass ein ThrombopoietinMimetikum wie Romiplostim durchaus eine Therapieoption bei Kindern mit chronischer ITP sein kann. Allerdings ist die Behandlungssowie Nachbeobachtungszeit der Studie zu kurz, um später auftretende unerwünschte Nebenwirkungen des Medikaments zu erfassen. Weiterhin muss die Indikation für Thrombopoietin-Mimetika kritisch diskutiert werden. Da die meisten Kinder mit ITP im Verlauf ihrer Erkrankung keine schwere Blutung erleiden, kann die Wirksamkeit eines Medikamentes nicht allein durch die Anhebung der Thrombozytenzahl bewiesen werden, sondern es muss die Effektivität des Medikamentes durch eine Verringerung der Inzidenz schwerer Blutungen bzw. der Letalität nachgewiesen werden. Dies kann jedoch nur wenn überhaupt - in großen internationalen Studien gezeigt werden.

Prof. Dr. Thomas Lehrnbecher

\section{Bocaviren als häufige Ursache einer Pneumonie bei Kindern}

Das humane Bocavirus (HBoV) ist ein neu identifiziertes Parvovirus, das häufig bei Kindern mit akuten Atemwegs- und Magen-Darm-Infektionen zu finden ist. Seine Bedeutung für die kindliche Pneumonie ist bisher unbekannt.

Ü ber einen Zeitraum von 15 Monaten wurden prospektiv 124 Kinder im Alter von einem Monat bis 15 Jahren, die bei Verdacht auf eine Pneumonie in Norditalien stationär aufgenommen worden waren, mithilfe serologischer Antikörpertests untersucht. Dabei wurden 16 verschiedene Mikroorganismen erfasst. 101 Kinder hatten eine radiologisch bestätigte Pneumonie.

Nach RSV-Infektionen, die bei $17 \%$ der Kinder auftraten, war eine HBoV-Infektion die zweithäufigste Ursache (12\%) für die Pneumonie. Sieben Kinder waren ausschließlich mit HBoV infiziert, während fünf Kinder gemischte Infektionen mit anderen Viren oder mit Bakterien aufwiesen. Elfmal wurde die Diagnose durch ein erhöhtes IgM, sechsmal durch einen Anstieg von IgG gestellt. Die Seropositivität für $\mathrm{HBoV}$ stieg altersabhängig und hatte mit Ende des Vorschulalters fast $100 \%$ erreicht. $\mathrm{HBoV}$ sind damit eine häufige Ursache der Pneumonie bei Säuglingen und Kleinkindern.

Don $\mathrm{M}$ et al. Serologically verified human Bocavirus pneumonia in children. Pediatr Pulmonol 2010; 45: 120-6

\title{
Was der Blick in den Hals bei V.a. Streptokokken verrät
}

Eine Streptokokken-Pharyngitis bei Kindern taugt nicht zur Blickdiagnose: Es gibt keine Symptome oder Krankheitszeichen, die - für sich allein oder in Kombination - die Infektion durch Streptokokken definitiv sichern oder ausschließen können. Trotzdem gibt es einige Befunde, die zumindest in Richtung Streptokokken-Infektion weisen. In einer systematischen Übersichtsarbeit wurden alle Veröffentlichungen aus den Jahren 1953 bis 2010 ausgewertet, die sich mit der Aussagekraft von Symptomen der StreptokokkenPharyngitis beschäftigten.

Es kristallisierten sich fünf Symptome heraus, bei denen immerhin eine über 50\%ige Wahrscheinlichkeit für eine Streptokokken-Pharyngitis bestand: 1. scarlatiniformes Exanthem, 2. palatinale Petechien, 3. pharyngeales Exsudat, 4. Erbrechen und 5. druckempfindliche Halslymphknoten. Einen deutlichen Hinweis auf ein geringes Streptokokken-Risiko liefert einer Studie zufolge die Kombination aus mindestens mittelschwerer Erkältung, höchstens leicht geschwollenen Halslymphknoten und Tonsillen und dem Fehlen eines scarlatiniformen Exanthems.

Dr. Beate Schumacher

Kommentar: HBoV sind nach RSV und Rhinoviren die dritthäufigsten Viren, die bei kleinen Kindern mit einer obstruktiven Bronchitis gefunden werden. Bei etwa 70-90\% der Kinder mit akutem Giemen finden sich im Rahmen einer virusinduzierten Atemwegsobstruktion serologische Hinweise auf HBoV. Bei etwa 10-20\% können in diesen Situationen HBoV aus den Atemwegssekreten identifiziert werden. Vorläufige seroepidemiologische Daten deuteten auf die Bedeutung von $\mathrm{HBoV}$ hin, da IgG-Antikörper bei über $90 \%$ der unter Sechsjährigen nachgewiesen werden.

Außerdem wird deutlich, dass entscheidend auf die Methodik und Definition der Infektion geachtet werden muss. Untersuchungen die nur auf dem Nukleinsäurenachweis (PCR) aus Sekreten beruhen und bei denen oft simultan weitere Viren gefunden werden, können die genaue pathogenetische Rolle von HBoV nicht einordnen.

Obgleich RSV-Infekte insbesondere zwischen November und Januar häufig vorkamen, hatte nur ein Kind eine Mischinfektion mit HBoV und RSV. Dies spricht für die unabhängige pathogenetische Bedeutung von HBoV für Pneumonien.

Dies ist die erste Studie, die klare Belege für die Rolle von HBoV bei Pneumonien liefert. Eine vorherige PCR-Untersuchung hatte das Virus bei 3,9\% der kindlichen Pneumonien identifiziert. Alle HBoV-positiven Pneumonien traten bei Kindern unter vier Jahren auf. Eine fast komplette Serokonversion ist bis zum Alter von sechs Jahren erreicht. Inwieweit die Antikörper protektiv wirken oder erneute Infektionen auftreten können, ist noch offen.

Prof. Dr. Matthias Griese

Shaikh N et al. J Pediatr 2011 Oct 31. [Epub ahead of print] 